\title{
Effect of Heating-Cooling Cycles on Electrical Behavior of Polymer Electrolytes
}

\author{
Iqbal M.I. Ismail \\ Department of Chemistry, Faculty of Science, \\ King Abdulaziz University, Jeddah, Saudi Arabia
}

\begin{abstract}
Frequency dependent conductivity of amorphous polymeric solid electrolyte containing $\mathrm{LiN}\left(\mathrm{SO}_{2} \mathrm{CF}_{3}\right)_{2}$ (LiTFSI) or $\mathrm{LiBF}_{4}$ was studied. Successive heating and cooling cycles showed changeable conductivity behavior, which was due to chemistry change in the lithium salts. Both salts showed a tendency of decreasing conductivity in the second cooling process. The decrease in conductivity behavior for samples containing $\mathrm{LiBF}_{4}$ was much higher if compared with those containing LiTFSI. Effect of heat on polymer network itself was not considered in this investigation.
\end{abstract}

\section{Introduction}

Polymer electrolytes have highly potential applications as solid electrolytes to advanced electrochemical devices such as high energy density solid batteries, electrochromic windows, sensors, and fuel cell. Global interest has especially focused on lithium/polymer electrolyte batteries as energy sources of electrical vehicles and for other mobile applications. This is because of their high energy density, safety, and the flexibility in both their shapes and production processes. Suitable mechanical strength, high ionic conductivity, and fast charge transfer at the electrode interfaces, electrochemical and physical property stability of these materials are assumed as main driving issues in polymer technology.

Among many kinds of polymer hosts, high molecular weight network polymers have many interesting characteristics ${ }^{[1,2]}$. However, these host polymers suffer from physical properties changes while using them, for example, in battery applications, i.e., due to overcharge or just because of the changeable ambient condition ${ }^{[3]}$. 
In this study, a network polymer prepared from a composition of two copolymers and mixed with a suitable Li-salt. The effect of heating-cooling cycles on conductivity measurements was investigated. The effect of Li-salt type was also considered.

\section{Experimental}

Host polymer made of two copolymers; $0.2 \mathrm{~g}$ mono-acrylated and $0.8 \mathrm{~g}$ tri-acrylated of ethylene oxide and propylene oxide (supplied by Dai-ichi Kogyo Seiyaku Co.) was mixed with appropriate weight of lithium salt. Oxygen atoms of both ethylene oxide and propylene oxide of copolymers were accounted to obtain desired lithium to oxygen ratio, $[\mathrm{Li} / \mathrm{O}]=0.08$. Two types of lithium salts were used; tetrafluoroborate $\left[\mathrm{LiBF}_{4}\right]$ (Tomiyama Chemicals), or lithium bis(trifluoromethylsulfonyl)imide [LiN $\left.\left(\mathrm{SO}_{2} \mathrm{CF}_{3}\right)_{2}\right]$, LiTFSI (supplied by IREQ). Both lithium salts were dried before use at $>150^{\circ} \mathrm{C}$ under reduced pressure for at least 24 hours.

Mixture of total of $1.0 \mathrm{~g}$ of copolymers together with appropriate weight of Li-salt, and 0.0006g of 2,2-dimethoxy-2-phenyl acetophenone (Ciba Geigy) as photo initiator were dissolved in $0.5 \mathrm{~g}$ of dry acetonitrile (Kanto Chemical Co. Inc.) inside the glovebox. The whole mixture was left to stir until a homogeneous clear solution was obtained.

Few drops of homogeneous viscous solution was spread between two glass plates separated by polytetrafluoroethylene spacer of $500 \mu \mathrm{m}$ and were sealed firmly by clips before irradiated with UV light $(250 \mathrm{~W}$ high pressure mercury lamp for $5 \mathrm{~min}$ ). Residual acetonitrile was evaporated under vacuum at room temperature. A transparent and flexible polymer electrolyte membrane with good mechanical strength was obtained. Polymer electrolyte film was cut into disk of $13 \mathrm{~mm}$ diameter and sandwiched between two symmetrical lithium electrodes and the whole was placed in a sealed cell and left in a temperature controlled chamber. Complex impedance measurement was carried out by using an $\mathrm{AC}$ impedance analyzer (Hewlett Packard 4192A) over $5 \mathrm{~Hz}$ to $13 \mathrm{MHz}$ frequency range at amplitude of $1.0 \mathrm{~V}$. A typical impedance spectrum in a complex plane diagram exhibited two regions; high frequency region is representative of the bulk impedance, whereas low frequency points correspond to interfacial impedance. $\mathrm{AC}$ impedance scans were obtained while cooling the furnace from 80 to $30^{\circ} \mathrm{C}$ at every $10^{\circ} \mathrm{C}$ of intervals. At least one hour allowed after reaching desired temperature for thermal equilibrium before taking the reading.

\section{Results and Discussion}

Examples of impedance diagrams for host polymer mixed with $\mathrm{LiBF}_{4} \mathrm{Li} /$ $\mathrm{O}=0.08$ during $1^{\text {st }}$ and $2^{\text {nd }}$ cooling processes at $80^{\circ} \mathrm{C}$, Fig. 1 . From larger scale in Fig. 2, one can observe the difference in bulk impedance between first and 


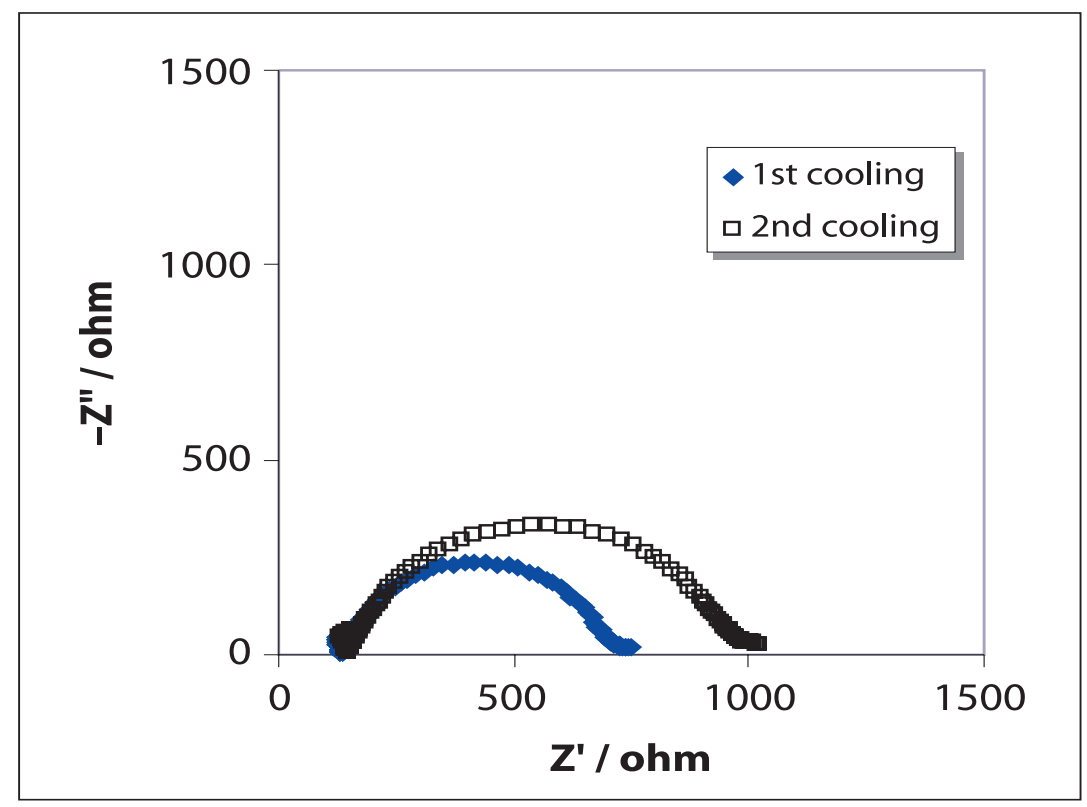

Fig. 1. AC impedance scan for $\mathrm{LiBF}_{4} / \operatorname{polymer}(\mathrm{Li} / \mathrm{O}=0.08)$ mixture at $80^{\circ} \mathrm{C}$.

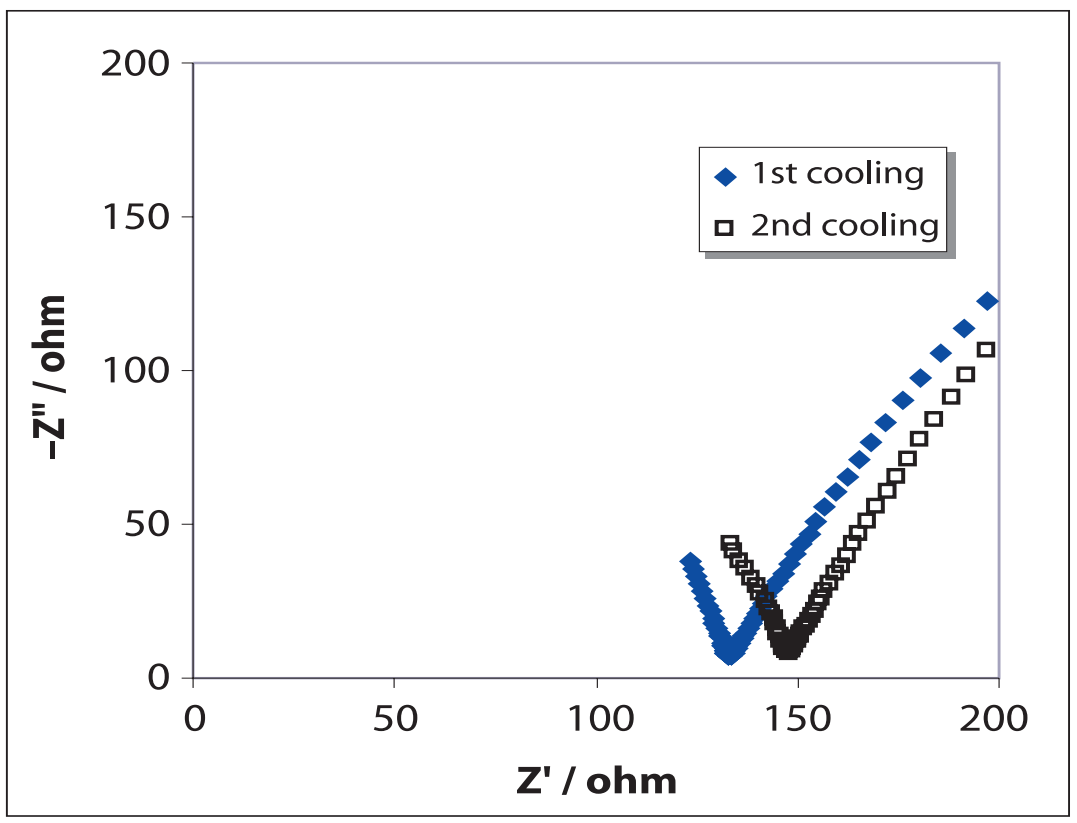

Fig. 2. As for Fig. 1 in larger scale. 
second cooling processes. About 7\% increase in bulk impedance is depicted due to subsequent heating-cooling process.

Figure 3 shows two successive cooling processes for the same sample used in Fig. 1 but throughout a wide range of temperature $\left(30-80^{\circ} \mathrm{C}\right)$. About $14 \%$ decrease in average in conductivity values between the two processes indicates that in spite of the advantages in $\mathrm{LiBF}_{4}$ salt when mixed with polymeric materials in various electrochemical applications ${ }^{[4,5]}$, its thermal instability weakens its importance. Polymer electrolytes contained LiTFSI salt behaved similarly (see Fig. 4), though maximum decrease in conductivity observed was no more than $7 \%$. Although in the latter sample lithium salt concentration was less than that used in the former, deteriorating electrical behavior in $\mathrm{LiBF}_{4}$-polymer mixtures was well reported by a number of investigators ${ }^{[6,7]}$. The presence of HF in both lithium salt mixtures is a main reason of forming insoluble $\mathrm{LiF}$ constituent in the polymer medium ${ }^{[8]}$, though, in a higher ratio in the case of $\mathrm{LiBF}_{4}$ salt. On the other hand, the increase in the interfacial impedance with about $30 \%$ between first and second cooling scan (see the right ends of the semicircles in Fig. 1) is another evidence for the formation of resistive film at the interface and that it may get thicker as it left in contact with the lithium metal for a long time and/or at elevated temperatures ${ }^{[9]}$.

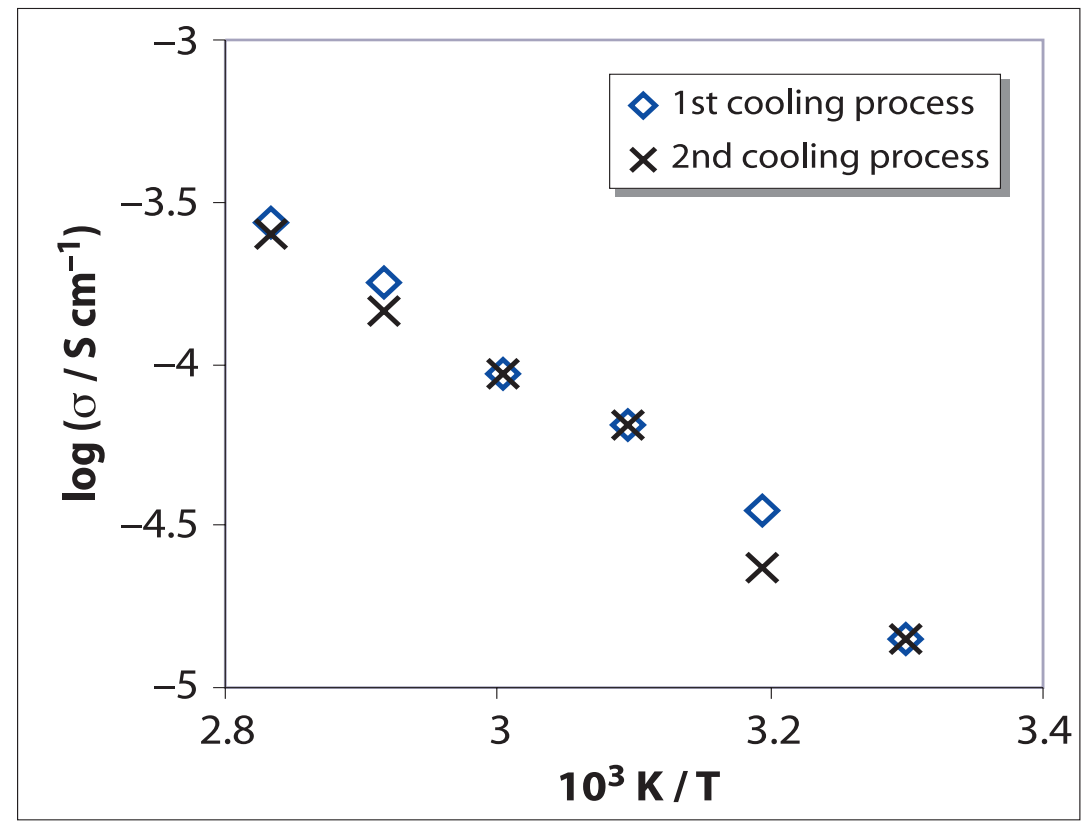

Fig. 3. Dependence of conductivity on reciprocal of temperature for $\mathrm{LiBF}_{4} /$ polymer mixture $(\mathrm{Li} / \mathrm{O}=\mathbf{0 . 0 8})$ for two successive cooling processes. 


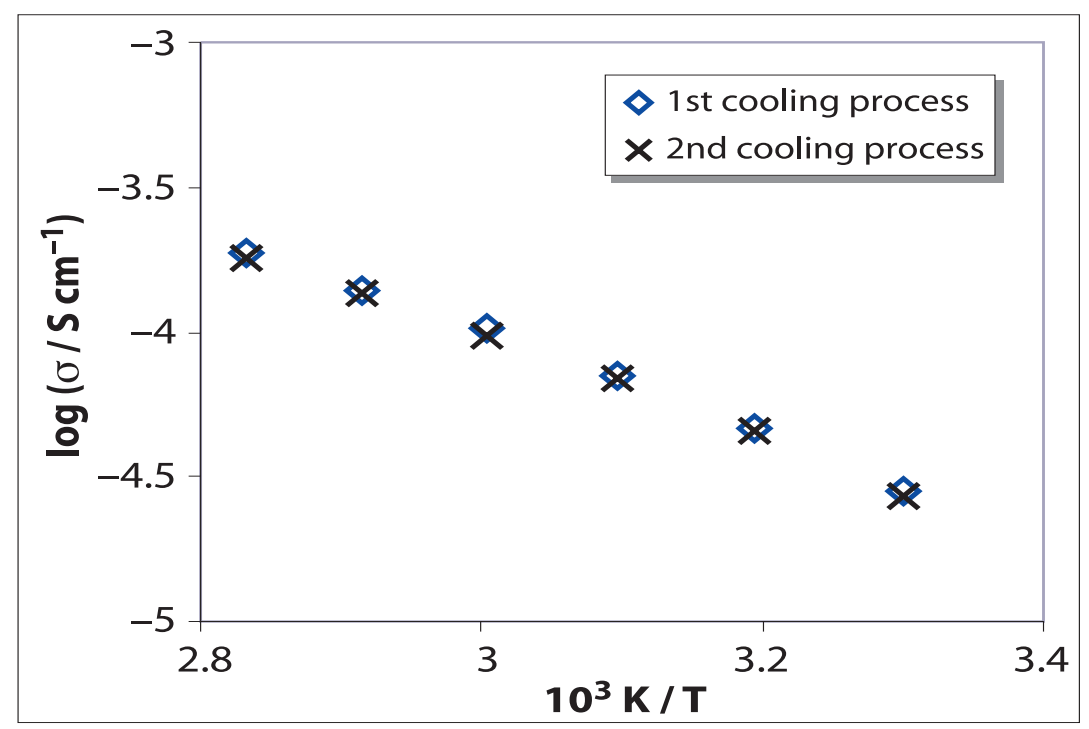

Fig. 4. Dependence of conductivity on reciprocal of temperature for LiTFSI/polymer mixture $(\mathrm{Li} / \mathrm{O}=0.01)$ for two successive cooling processes.

Figure 5 indicates that ionic conductivity for polymer/LiTFSI electrolyte is as double as that for polymer/LiBF 4 throughout the temperature range. This variation in the ionic conductivity is due to the plasticizing effect in LiTFSI salt which depresses crystallinity and enhances ionic mobility causing higher conductivity ${ }^{[10]}$.

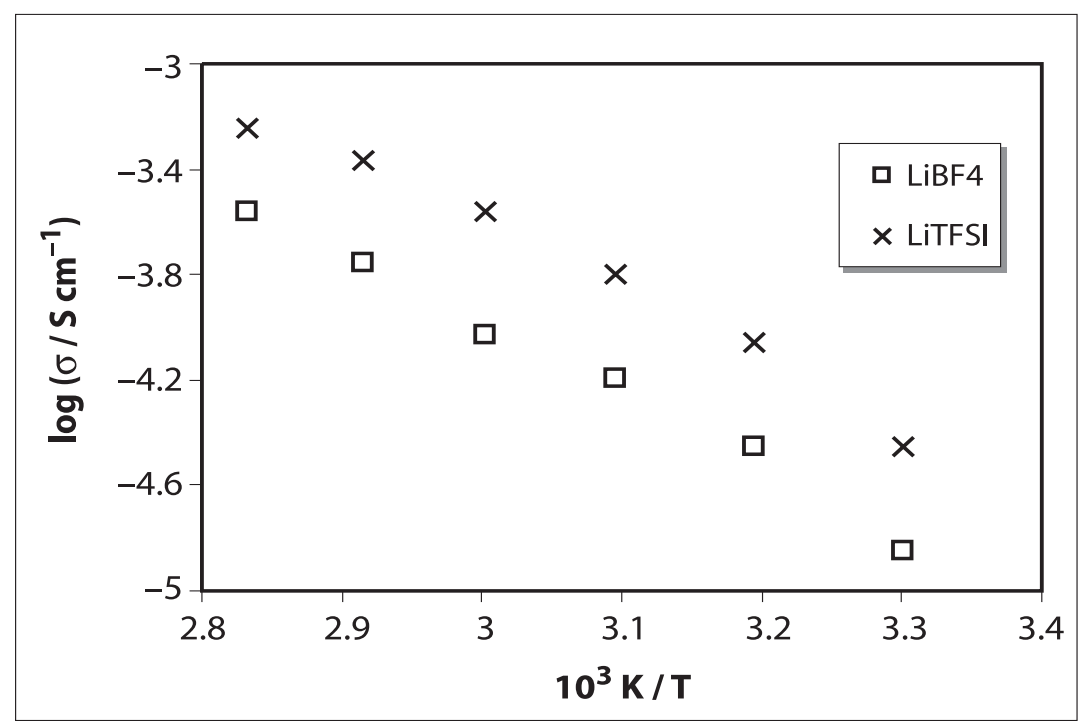

Fig. 5. Dependence of ionic conductivity on type of lithium salt $[\mathrm{Li} / \mathrm{O}=0.08]\left(1^{\text {st }}\right.$ cooling scan $)$. 


\section{Conclusion}

Both bulk and interfacial impedances increase as polymer electrolyte sample attached to $\mathrm{Li}$ foil is exposed to elevated temperatures. Polymer/ $\mathrm{LiBF}_{4}$ mixture showed worse behavior due to higher ability to lithium salt decomposition which increases with temperature. Plasticizing effect of LiTFSI salt enhances its polymer electrolyte conductivity.

\section{References}

[1] Nishimoto, A., Watanabe, M., Ikeda, Y. and Kohjiya, S., Electrochemica Acta, 43: 1177 (1998).

[2] Watanabe, M., Hirakimoto, T., Mutoh, S. and Nishimoto, A., Solid State Ionics, 148: 399 (2002).

[3] Ansari, R. and Wallace, G.G., Polymer, 35: 2372 (1994).

[4] Lisowska-Oleksiak, A., Solid State Ionics, 119: 205 (1999).

[5] Selvaraj, I.I., Chaklanobis, S. and Chandrasekhar, V., J. Electrochem. Soc., 142: 366 (1995).

[6] Aurbach, D., Daroux, M.L., Faguy, P.W. and Yeager, E.B., J. Electrochem. Soc., 134: 1611 (1987).

[7] Kanamura, K., Shiraishi, S., Tamura, H. and Takehara, Z., J. Electrochem. Soc., 141: 2379 (1994).

[8] Kanamura, K., Tamura, H. and Takehara, Z., J. Electroanal. Chem., 333: 127 (1992).

[9] Ismail, I., Noda, A. Nishimoto, A. and Watanabe, M., Electrochemica Acta, 46: 1595 (2001).

[10] Walker Jr., C.W. and Salomon, M., J. Electrochem. Soc., 140: 3409 (1993). 


\title{
تأثير دورة التسخين - التبريد على السلوك الكهربائي للإلكتروليتات المبلمرة
}

\author{
إقبال محمد إبر اهيم إسماعيل

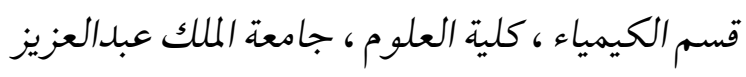

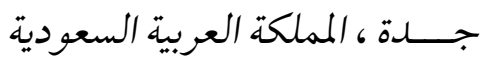

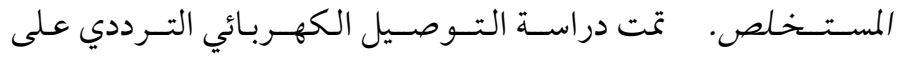

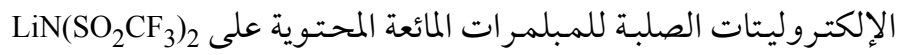

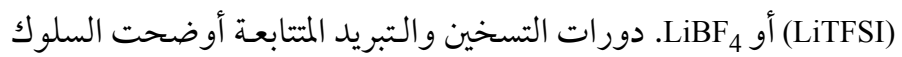

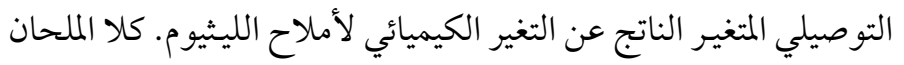

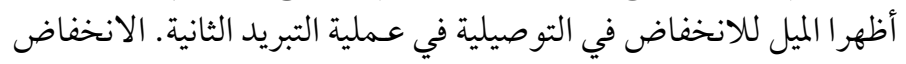

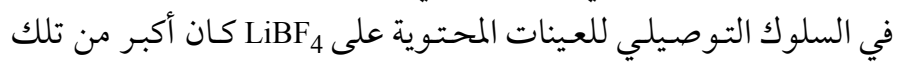

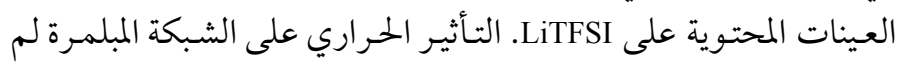
يؤخذ بعين الاعتبار في هذه الدراسة. 